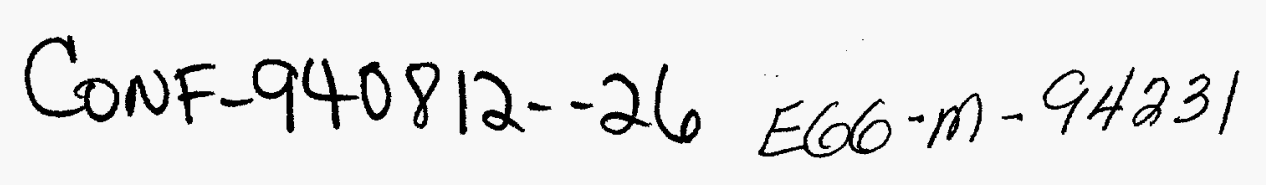

\title{
A MIDDLE PATH FOR ELECTRICITY OPTIONS AND SUSTAINABLE DEVELOPMENT ${ }^{\mathrm{a}}$
}

\author{
James I. Mills and J. Stephen Herring \\ Idaho National Engineering Laboratory \\ Idaho Falls, Idaho 83415-3815
}

Abstract

In a landmark article in Foreign Affairs in October $1976^{1}$, Amory Lovins presented his vision of two vastly different and seemingly irreconcilable paths that energy provision might take into the future. One path was a "hard" path, characterized by extensive development of large, capital-intensive centralized electrical generating facilities and their peripherals, designed with little consideration given to the matching of these facilities to the requirements of the end-use needs. The second, "soft" path was characterized by energy technologies that are diverse, operate on renewable energy flows, are relatively simple, less capital-intensive, and matched in scale and energy quality to end-use needs. One of the most controversial arguments in the Lovins' paper was that the "hard" and "soft" paths are culturally and institutionally antagonistic. In retrospect, it seems this argument was self-fulfilling, for the history of the energy debate throughout the developed world since the appearance of the Lovins' article has been marked by an either-or antagonism that has left little room for serious discussion of a "middle-path." In this paper, we argue that a "middle-path," paved with elements of both the soft and hard, is especially suited for developing countries, since they do not now carry the burden of an existing and extensive "hard path" energy infrastructure.

\section{Introduction}

Providing electrical energy to preindustrial countries in an environmentally responsible and sustainable manner will be a major challenge of the next 30 years. As noted recently by Gerard $\mathrm{Piel}^{2}$ and Mcadows, et.al. ${ }^{3}$, reducing population growth to a sustainable steady state value is a product of the improved health and living conditions brought on by a well-considered development. Improving the availability and reliability of the electric supply is an integral part of that development.

Many current projects for providing power to preindustrial countries involve the construction of large hydro-electric dams, leading to population displacement and flooding of badly-needed agricultural land and important forest reserves. The construction of conventional fossil and nuclear plants requires that the developing countries first develop an infrastructure for both the construction and operation of such plants. Many of the preindustrial countries have indigenous coal reserves which can result in significant pollution and other environmental degradations if not burned with the best available technology. Both hydro and steam plants require significant capital investments, either by the host country or by outside development agencies, before the first kilowatt-hour is delivered.

Improvements in ocean transportation of bulk and finished goods over the last 20 years have made the oceans disappear as barriers to commerce. Thus, tarifffree zones surrounding major ports are becoming a major vehicle for development and gateways to the global economy. By providing the needed electricity to power these enterprise zones, US technology could furnish a vital link in development.

Several technologies could be used to provide electricity from a mobile platform. The Babcock and Wilcox Company has built barge-mounted gas turbines for use in developing countries. These turbines, powered by either natural gas or oil, are anchored near the shore. Other offshore technologies could also be imagined. Coal-fired units, for example, incorporating filters and scrubbers could be barge-mounted and fueled via a short conveyor from shore. Submerged nuclear power stations, located $10-30 \mathrm{~km}$ offshore, have also been proposed.

Many of the potential sites for mobile power sources are in rapidly industrializing countries around the Pacific Rim, all of which have rapidly growing needs for power, a shortage of land on which to site conventional power stations, and a developing industrial base concentrated around major coastal cities.

In addition to the potential for developing efficient energy infrastructure in response to the needs of rapidly developing urban coastal areas, important opportunities also exist to address the socio-economic changes and resultant changes in energy demand that are unique to traditionally agrarian rural areas. Maintenance of environmentally sound traditional practices, complemented by the development of rural or "inland enterprise zones," sustained by appropriate technologies fueled by renewable energy resources, could lead to growth of light and cottage industry that would broaden the economic base of these rural areas while simultaneously allowing for the maintenance of traditional environmental and cultural values.

An energy infrastructure development strategy responsive to the developing needs and unique requirements of both urban and rural areas demands a complex portfolio of efficient energy technologies leading to industrialization with minimized environmental impact. Furthermore, if this infrastructure is built upon a foundation of advanced technologies, important international trade opportunities for high-technology goods and services in large and expanding markets will develop.

a This work was supported under U.S. Department of Energy, Idaho Operations Office Contract No. DE-AC07-76IDO1570.

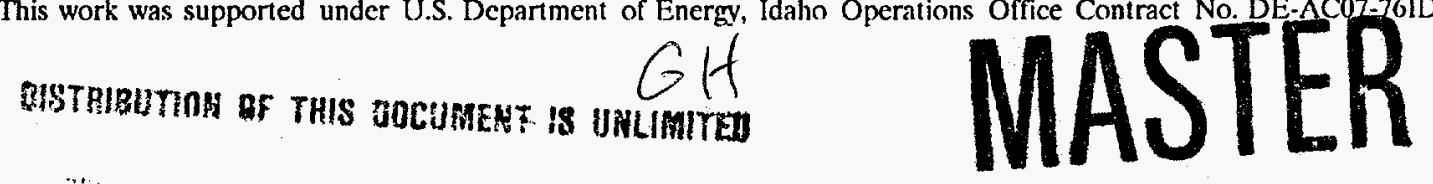




\section{Demographics of the developing world}

The rapid growth in population in the developing countries is an issue with which the entire world community, both industrialized and preindustrial, must contend in the coming decades. The 1993 annual survey of the Population Reference Bureau ${ }^{4}$ showed that the world population is 5.5 billion and growing at $1.6 \%$ per year. Most of the growth is in the preindustrial countries of Africa, Asia and South America. The United States, growing at $0.8 \%$ per year, is the only large industrialized country with a growth rate above $0.5 \%$ per year. Rising population inevitably increases pressure on resources, food and living space. In addition, increasing populations need energy to raise productivity and drive their economies.

In the EPRI Journal of June 1992, Robert $\mathrm{Fri}^{5}$, in his article addressing the challenge of global sustainability, posits that "if the per capita income of the majority of the world's people were to rise to only onethird of that which the developed countries might enjoy a century from now, then the world economy would have to expand in real terms by 30 -fold over the next 100 years." The use of energy and particularly electricity varies widely among the countries of the world. Figure 1 shows the cumulative world population using less than a given amount of electricity. About 3.5 billion people use less than $100 \mathrm{~W}$ per capita, averaged around the clock and throughout the year. About 2.2 billion use less than $50 \mathrm{~W}$ per capita. The names of the individual countries in the figure have been moved horizontally for clarity, but not vertically. Several familiar industrialized countries are well off the top of the figure. US average electrical use is $1365 \mathrm{~W}$ and that of Japan is $723 \mathrm{~W}$ per capita. Other values are shown on Figure 2.

To add near-term perspective to the issue of energy demand growth, the U.S. Agency for International Development (USAID) estimated in 1988 that if the performance of power systems in the developing world remains the same as today, and economic growth averages $4.5 \%$ per year, the developing nations as a group would require $1500 \mathrm{GWe}$ of additional generating capacity between 1988 and $2008 .^{\circ}$

The amount of additional generating capacity required as a function of increases in per capita use is shown graphically in Figure 2. On this graph we see, for example, that if we want to raise those 3.5 billion people now having < $100 \mathrm{~W}$ per capita to $100 \mathrm{~W}$, we would require 500 plants of $600 \mathrm{MWe}$ each (or 5000 plants of $60 \mathrm{MWe}$ each). Figure 2 also shows the generating levels of several countries, along with an estimate by the Office of Technology Assessment in 1992 of the level (352 W per capita) to which the demand in the preindustrial countries might be held through the use of energy efficient technologies. Figure 2 does not allow for population growth in the future, but only shows the capacity needed to meet the demands of the present population.

Even if aggressive steps were taken to increase the efficiency of the energy infrastructure in the developing countries by $25 \%$, which USAID estimates could be accomplished through improvements in electricity generating efficiency, sharp reductions in transmission and distribution losses, and increases in electricity end- use efficiency, an additional 1875 generating plants (600 MWe each) would be required. If these projections are accurate, and if the requirement is to be met, then the following three major questions are among those that must be raised and resolved:

1. How can energy resources be managed in a way that allows near-term needs to be met without compromising the ability of future generations to meet their own needs?

2. How will the energy requirements of the developing countries be satisfied within the framework of minimization of potential global, regional and transboundary environmental problems?

3. What infrastructure development strategy offers the most economic and environmentally sound approach to the addition of generating capacity?

The objective of this study is to begin to address the above questions by applying a strategy based upon the establishment of "coastal enterprise zones," served by mobile offshore, highly efficient, generating plants, together with the complementary development of "inland enterprise zones" that make use of the most efficient de-centralized appropriate technologies and regional renewable resources. These two zones "communicate" with each other and are linked through an efficient transportation infrastructure. For the purpose of this work, energy technologies are understood to include conservation as well as conversion and utilization technologies.

Strategic planning for future energy infrastructure, especially in the developing countries, will depend in large part on an accurate understanding of the complex dynamics of population growth as functions of education, economic welfare, infant mortality rates, public health access and other parameters.

As an example of one strong apparent influence on population growth dynamics, several demographers have recently shown that education and prosperity are effective means for curtailing population growth. Figure 3 is a scatter-plot of population growth versus female literacy in a number of countries. ${ }^{7}$ Although there is a wide distribution in the points, the trend toward slower population growth with increased education is evident.

Population growth also appears to be a strong function of the rate of industrialization. The relationship between population growth and the per capita electric use is shown in Figure 4. While several of the OPEC countries have both high population growth and a high electric availability, most of the other countries in the world follow a clear trend. Since electricity use is closely correlated with GDP, one would expect to see a similar trend in population growth as a function of GDP.

At least in the short term, improving health care and reduction of infant mortality appear to offset the decline of population as brought about by increasing education and GDP. In fact, the general health of the population, as evidenced by life expectancy, improves rapidly with growing GDP. As a country's GDP increases, life expectancy increases much sooner than the birth rate declines ${ }^{\mathrm{E}}$. Thus, population increases rapidly during the transition to industrialization. 


\section{DISCLAIMER}

This report was prepared as an account of work sponsored by an agency of the United States Government. Neither the United States Government nor any agency thereof, nor any of their employees, makes any warranty, express or implied, or assumes any legal liability or responsibility for the accuracy, completeness, or usefulness of any information, apparatus, product, or process disclosed, or represents that its use would not infringe privately owned rights. Reference herein to any specific commercial product, process, or service by trade name, trademark, manufacturer, or otherwise does not necessarily constitute or imply its endorsement, recommendation, or favoring by the United States Government or any agency thereof. The views and opinions of authors expressed herein do not necessarily state or reflect those of the United States Government or any agency thereof. 


\section{DISCLAIMER}

Portions of this document may be illegible in electronic image products. Images are produced from the best available original document. 


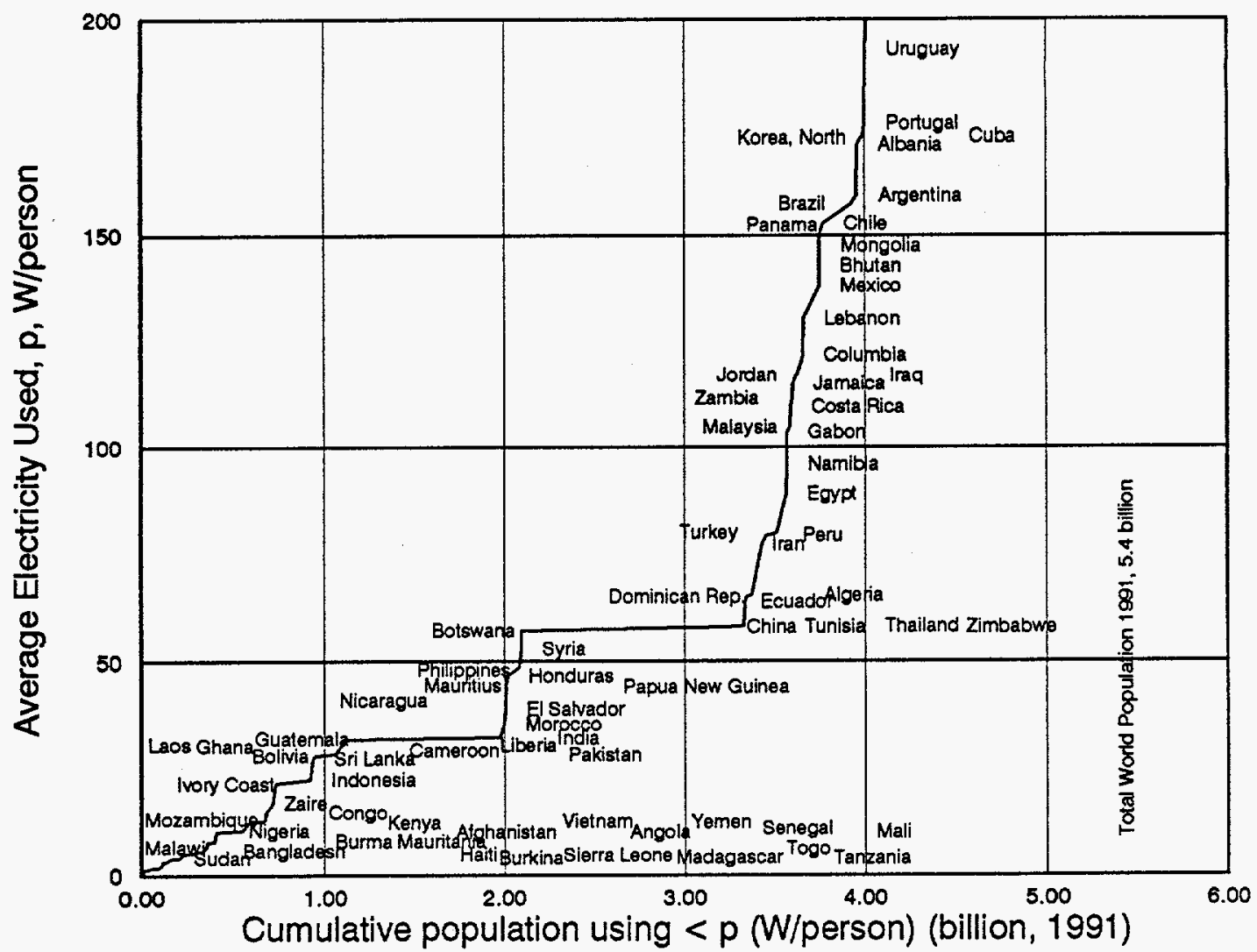

Figure 1

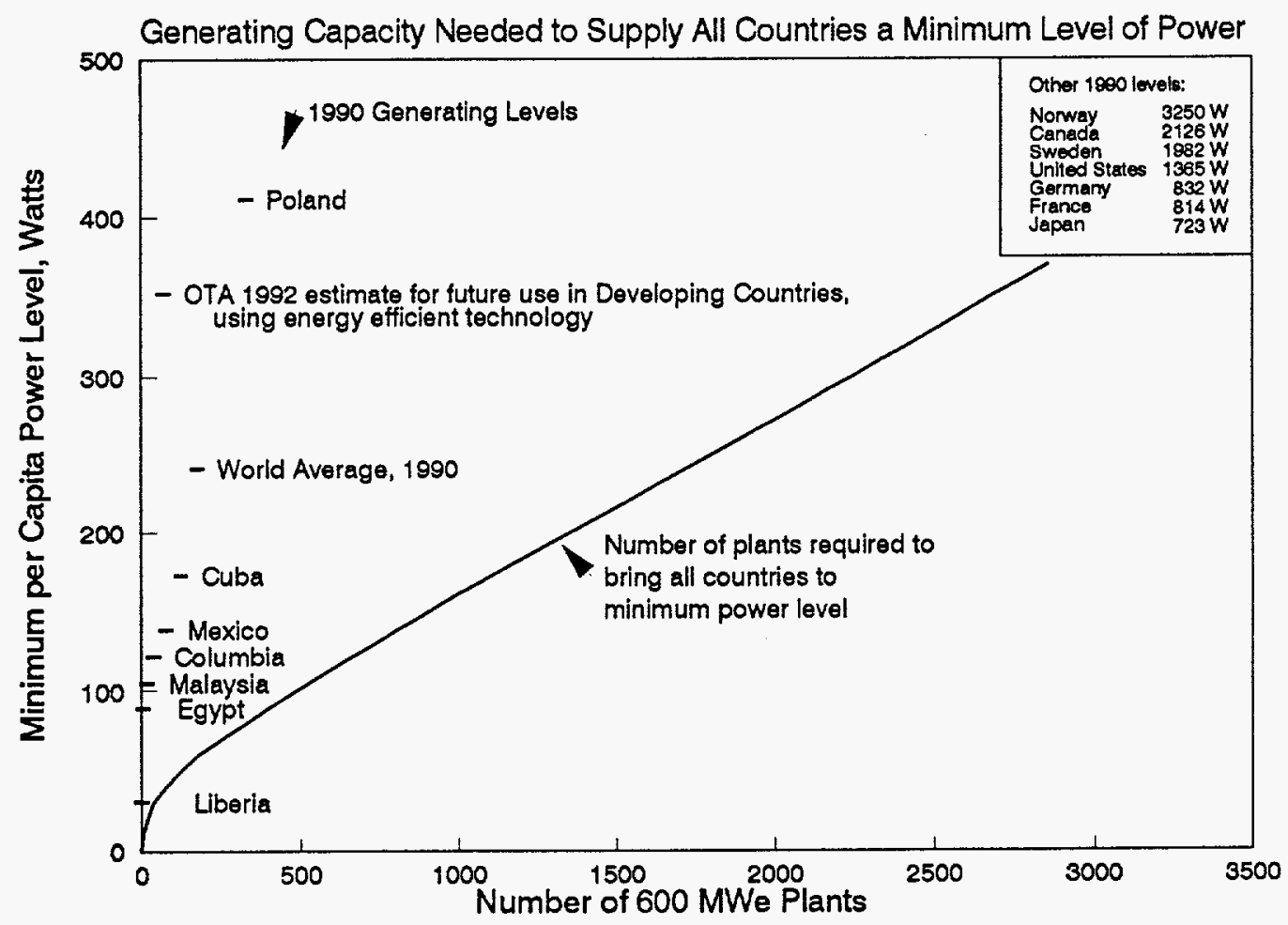

Figure 2 


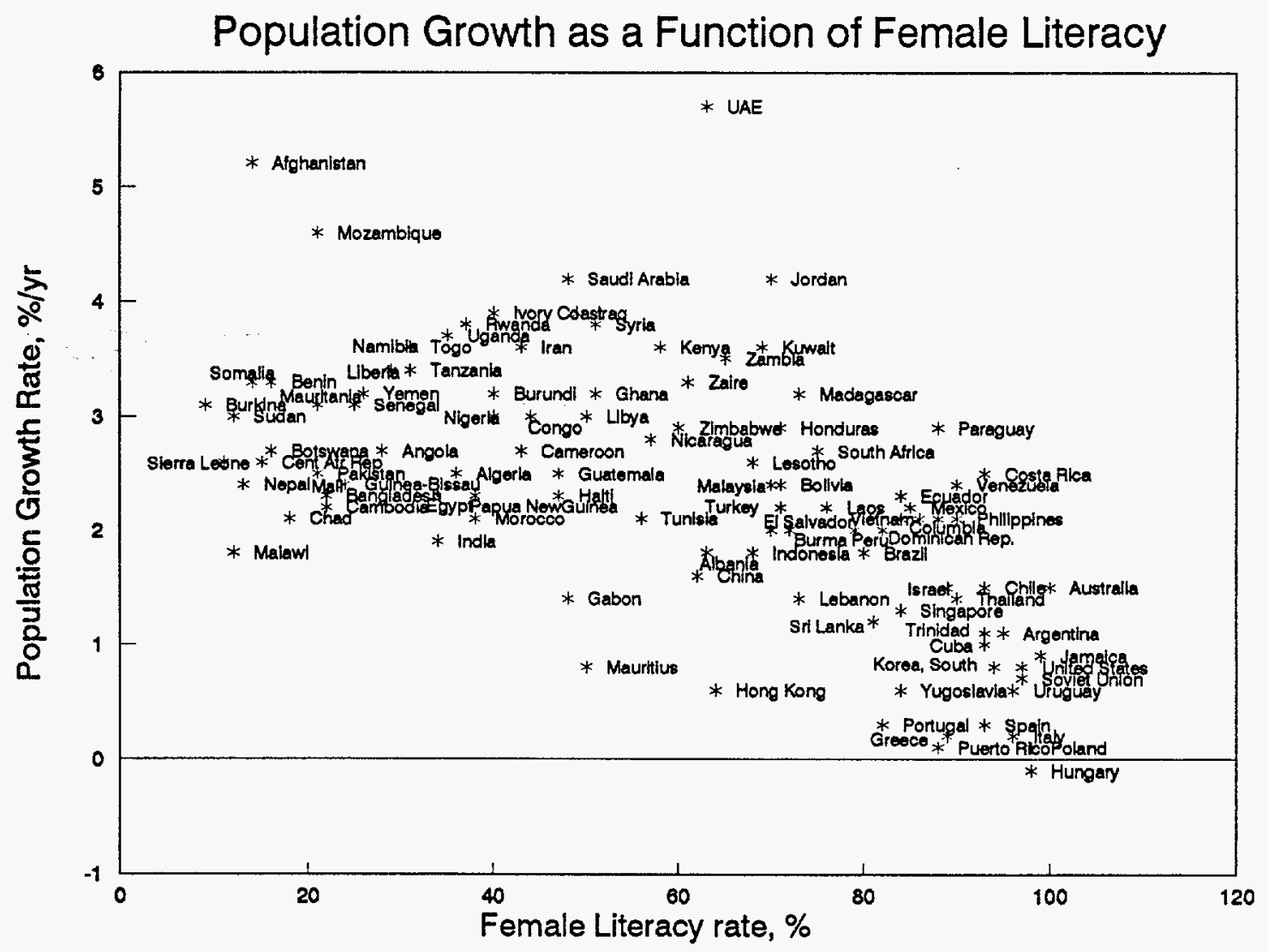

Figure 3

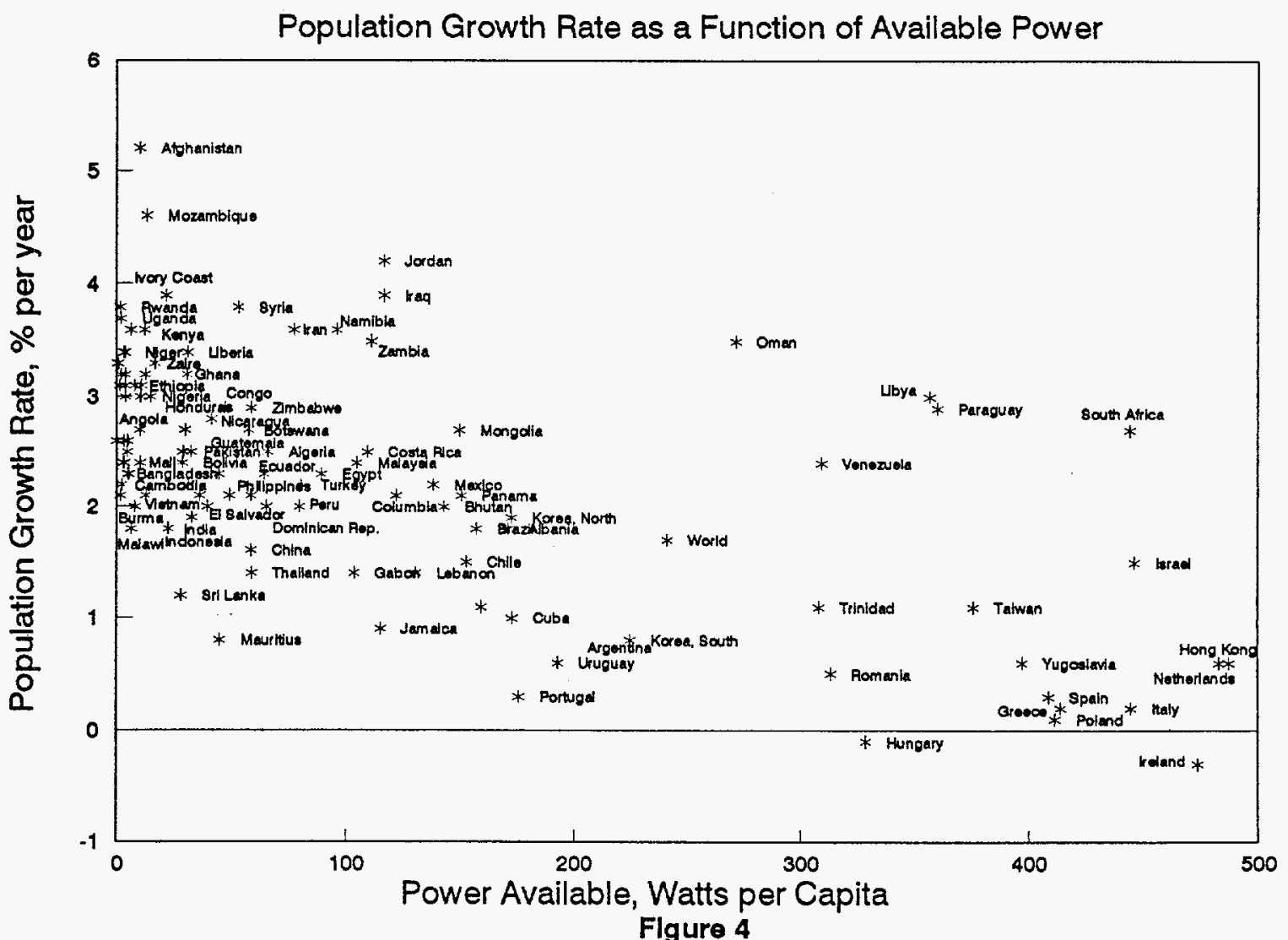

FIgure 4 
As a further influence on strategic energy infrastructure planning, the complex dynamics of population growth leads to dramatically different rates of growth in rural and urban areas. Also, the differences in economic activities between rural and urban populations lead to different requirements for energy growth, suggesting the parallel development of efficient energy infrastructure that is responsive to patterns of regional need and use as well as to the absolute magnitude of energy demand. The boundary between rural and urban, coastal populations is one example of an obvious natural system boundary that can be drawn for the purpose of strategic energy infrastructure development.

\section{Coastal populations}

Populations in both the preindustrial and industrialized countries are concentrating in urban centers and particularly in coastal urban centers. In the US, $53.4 \%$ of the resident population lives within 50 miles of a coastal shoreline (including the Great Lakes). ${ }^{9}$ Table 1 shows the 25 largest cities in the world in the year 2000 .

Table 1 Megacities in the year 2000

\begin{tabular}{|lr|}
\hline \multicolumn{2}{|c|}{25 Largest Cities in 2000} \\
(million)
\end{tabular}

Note that the population of those cities that are both coastal and in preindustrial countries is 174 million. As developing countries experience increasing urbanization, the urban commercial, industrial and transportation infrastructure will grow in proportion. Energy demand in these urban areas is further accelerated by increasing demands for lighting, transportation, and general consumer goods. Thus, as population grows and countries industrialize, both population growth and energy demand grow faster in urban areas than in their rural neighbors. This rapid growth can be most easily accommodated by deployment of standardized, modular energy technologies that are quickly responsive to demand and minimize infrastructure development. One way of accomplishing this is through deployment of offshore facilities. By providing the technology for offshore generation to supply needed electricity to these "coastal enterprise zones," the U.S. and other developed countries could furnish a vital link in the establishment of efficient, cost-effective and environmentally responsive energy infrastructure.

The electricity could be purchased on an as-used basis, thus reducing the capital investment needed in promoting the country's development. The electricity might be provided on a short-term or long-term basis. If the generating equipment is movable, outside investors would have fewer worries about the changing demand for power, the emergence of lower-cost alternatives or nationalization by the host government. Furthermore, the units could be mass-produced in a central facility, reducing the per-unit costs.

\section{Inland Populations}

As growing populations in preindustrial countries continue to concentrate in coastal urban centers, demand for and acceptance of more sophisticated technologies, including energy technologies, will follow. Conversely, primarily agrarian, "inland" populations have less need or opportunity to develop the complex infrastructure that must exist to support large, centralized electrical generating stations. Instead, there exists in these agrarian centers an equally critical need for the rapid development and marketing of efficient, affordable energy conversion and utilization technologies that optimize the use of local resources while simultaneously minimizing both local and global environmental impacts. However, it must be noted that the environmental practices of traditional cultures applied in the process of supplying their own needs are generally quite benign. For example, consider deforestation, a practice generally associated with agrarian cultures and one which has a literally incalculable adverse impact on the global environment. About twice as much carbon dioxide is taken up by photosynthesis on land as in the oceans and rivers; every hectare of tropical forest burned releases between 350 and 700 tons of carbon dioxide into the atmosphere. (Data from 1990-1991, published by the World Resources Institute, suggests that the world is losing up to 20.4 million hectares of tropical forest annually ${ }^{10}$ ) Tropical forests also provide habitat for at least half of the world's species, provide homes and resources for indigenous peoples, and are an increasing source of globally important medicines and other products. In spite of the serious- 
ness of deforestation, rural collection of traditional wood fuels, which is the major primary direct use of forest products in agrarian cultures, is not a significant contributor to the problem. In fact, forest dwellers exhibit a strong awareness of the impact of deforestation, and movements by indigenous peoples to press for forest conservation appear to be increasing. In Kenya, as one of the earliest and most famous examples, women, in reaction to being forced by deforestation to walk farther and farther to collect fuel, banded together to form the Green Belt Movement in 1977. Since then, Green Belt has provided deforestation awareness, planted nearly five million trees and established community nurseries across Kenya. ${ }^{11}$ As Paztor and Kristoferson $^{12}$ show, deforestation is driven not by rural uses of wood but instead by urban requirements for fuel and food, emphasizing again the need to focus developing country energy infrastructure initiatives in rapidly growing urban areas.

Given the perspective that traditional agrarian energy and agricultural practices are relatively benign relative to their impact on the local or global environment, energy development initiatives in rural areas should proceed with two major objectives:

1) improving of the quality of life, including expanded educational opportunities, which leads to a direct impact on population growth; and

2) the establishment of markets for emerging, appropriate technologies, such as photovoltaics and other local use and resource specific technologies, which in turn would lead to environmentally sound and potentially cost-effective energy infrastructure development, with little consequent disruption of traditional energy or agricultural practices.

The availability of more plentiful energy in rural areas of developing countries could lead to the establishment of "inland enterprise zones" founded upon an existing infrastructure of traditional practices together with an increased availability of decentralized usespecific and resource-appropriate technologies. Opportunities for the development of light and cottage industry within these zones would in turn lead to an enhanced economic base and a subsequent reduced need to market precious natural resources, such as the rainforest, to local or global urban interests.

\section{Conclusions}

If the energy needs of an increasingly industrialized world are to be met within a framework of sustainable global environment, careful thought and global cooperation must be marshalled against the chalienge of developing the energy infrastructure required by rapidly developing countries. Success in developing an infrastructure that optimizes use of energy resources through conservation and the application of a portfolio of environmentally sound and cost-effective traditional, emerging and advanced technologies not only represents the best possible approach to turn the rising tide of global environmental degradation, but such a strategy also leads to growing international markets for advanced energy technologies. In turn, this potentially large and growing market offers opportunities for the developed countries to more easily transition their defense industries to high technology energy and manufacturing products and related services.

If the strategy of efficient energy infrastructure development in response to specific need and use characteristics is to be realized, we must depart from the traditionally proposed choice of either economies built solely on large centralized energy technologies or economies relying exclusively on conservation and the use of renewable, "appropriate" technologies. Instead, we suggest planning the energy infrastructure of developing countries (with significant shoreline) in ways that are responsive to the unique characteristics of rural "inland" areas and coastal areas where population growth and industrialization will be greatest. This strategy, which must be based on systems analyses that optimize against environmental, economic, resource and market parameters, among others, will lead to a complex infrastructure that has the inherent capability to accommodate both large centralized and small decentralized generating capacity, which will in turn depend upon an equally complex portfolio of renewable and conventional, traditional and advanced energy resources and technologies.

If, through the collaborative global marshalling of technology and will, the energy infrastructure of the developing countries can be pursued in a manner that leads to sustainable demands on our stock of natural and environmental resources then perhaps we can begin to meet the needs of the present without compromising the welfare of generations yet to come.

\section{References}

1. Lovins, Amory B.; "Energy Strategy: The Road Not Taken?," Foreign Affairs, October 1976.

2. Piel, Gerard; Only One World, W. H. Freeman and Company, New York, 1992.

3. Meadows, Donella H., Dennis L. Meadows and Jørgen Randers; Beyond the Limits, Chelsea Green Publishing Company, Post Mills, Vermont, 1992.

4. "Population Explodes in Third World, Slows Elsewhere," Associated Press, May 12, 1993.

5. Fri, Robert; "The Challenge of Global Sustainability," EPRI Journal, June 1992

6. U.S. Agency for International Development, "Power shortages in Developing Countries: Magnitude, Impacts, Solutions and the Role of the Private Sector," March 1988.

7. The World Factbook, 1992, Central Intelligence Agency, Washington, DC 20505.

8. op.cit., 3, p. 30-31.

9. U.S. Bureau of the Census, Statistical Abstract of the United States: 1992, (112th edition.) Table 32, page 28, Washington, DC, 1992.

10. The World Resources Institute, World Resources: A Guide to the Global Environment, Oxford University Press, 1990, p. 102.

11. op. cit. 7, p. 110.

12. Paztor, Janos and Lars Kristoferson, "Biomass Energy," The Energy Environment Connection, edited by Jack M. Hollander, Island Press, 1992, Chapter 7, pp. 178-179. 